\title{
RECOVERY AND OPTIMIZATION OF A FORMER RAILWAY TRANSPORT TRACK
}

\author{
GIULIA FORESTIERI $^{1}$, GUIDO MARSEGLIA ${ }^{2} \&$ GIUSEPPE GALIANO $^{3}$ \\ ${ }^{1}$ Facultad de Ingeniería, Universidad de La Sabana, Campus Universitario del Puente del Común, km 7 Autopista \\ norte de Bogotá, Chía, Cundinamarca, Colombia \\ ${ }^{2}$ Università degli Studi Link Campus University, Italy \\ ${ }^{3}$ Department of Civil, Building and Environmental Engineering, Sapienza University of Rome, Italy
}

\begin{abstract}
According to the new European standards on pollutant emissions and improving air quality levels, the choice of low environmental impact systems of transport is fundamental. The requalification of disused railway transport today assumes an important role for the sustainability of the city and its building infrastructures. In particular, the reutilization of abandoned infrastructures, such as brownfield railways, allows the possibility of realizing travel systems with low pollutant concentrations. Railway rehabilitation designs respond to the actual requalification policies that are discouraging new exploitations, stopping degradation phenomenon and protecting incessancy of the environment, by means of not affecting the environment with new infrastructures. This paper presents the application of actual urban strategies, presenting a design proposal of requalification and optimization of the former railway transport track in Calabria, a region of southern Italy. Results show the possible solutions in terms of environmental and economic benefits obtained thanks to the use of an urban sustainable design. Moreover, social and tourist implications are highlighted.
\end{abstract}

Keywords: transport, railway, sustainability, urban rehabilitation.

\section{INTRODUCTION}

The restructuring of the transportation sector in order to respect the European climate standards assumes a fundamental role. The recent 2030 agenda of the United Nations defines "17 Sustainable Development Goals (SDGs)", taking into account a wide range of worldwide issues, including that infrastructures and cities and human settlements are made inclusive, safe, resilient and sustainable, achieving a high quality life [1], [2]. In particular, the growing attention in the logistics field is moving various researchers towards efficient and efficacy methodologies that permit the development and optimization of processes. Especially in the transport sector, logistics' actual challenge aims to allow and manage the need for infrastructure for the storage of goods, in an efficient time, in a safe way, with low costs and zero environmental impact.

Concerning the air quality question, the transport of people and goods by trains, ships, cars and aircrafts is one of the most important issues of the pollutant concentration of the greenhouse gases (GHGs) [3]-[5]. Within the general framework of logistics, the restructuration of railway itinerary belongs to the transportation sector [6]-[10]. Marzano et al. [11] developed a methodology based on encouraging railway industries to resolve an infrastructural gap on the rail network in Italy, considering the optimal European statistics. Their study also aimed to obtain a higher capacity and lower transport prices, thanks to economies of scale.

Nowadays, the redevelopment of disused railway sites to reach environmental and economic benefits is a main topic considered in various researches [12]. Moreover, other advantages are represented in the fact that some railway brownfields present low reclamation costs in respect to the previous former industry zones. The requalification of disused railway areas is increasing due to the management of national railway systems, causing the spin-off 
of real estate market due to the expansion of large city brownfields [11]. In this perspective, railway brownfields are considered a key topic in city and infrastructure restructuration projects.

With regard to the requalification of abandoned railway lines in urban and rural areas, recent researches investigate using the development of a specific methodology that allows one to manage decision-making processes and to support the estimation of the environmental impact of various transport systems [13].

This paper focuses on the recovery and optimization of the former railway transport track by means of a zero environmental impact system, a bike lane, in Calabria, a region of southern Italy. The main issues in the realization of bike sharing in the zone of Calabria Region are highlighted, with the environmental, economic, social and tourist impacts also being discussed.

\subsection{Mobility, transport and territory}

The need of mobility for human beings represents one of the most ancient motivations. This need involves the individual person, and then project proposals designing the external world. According to these needs, the concept of "transport" is born [14]. The first requirements are linked to the need of mobilizing goods. In a second step, the issue starts involving people, giving rise to the phenomenon known as "commuting" [14]. Wheels, tree branches and trunks for river navigation represent the first means of transport. Archaeologists attribute the introduction of the wheel to the Sumerians, around $3500 \mathrm{BC}$, until we reach recent eras when men have been able to take advantage of the strength of the wind for navigation and of the strength of animals for ground transportation.

During the 16th century the first rail appears, principally made of wood and then also equipped with metal reinforcements. Successively, in the 18th century, iron substitutes wood in order to guarantee the rail network more durability. In the 19th century new forms of energy are discovered, determining a revolution destined to change society in all its aspects. The steam engine for maritime navigation, the development of rail transport and electricity are some of the most representative discoveries of this century. Railway maintains the main role among the means of transport towards the end of the 19th century. Events related to the First World War, however, give a decisive boost to the development of road transport and at the same time a serious blow to the railway system. On the eve of the Second World War, transport was characterized by a railway network of $1.336 .000 \mathrm{~km}$ and by 45 million cars circulating, constituting $35 \%$ of the land transport [15].

In the post-war reconstruction period, in some European countries like Italy, the motor scooter appears, even though the car represents the main means of transport of the 20th century. Nowadays, each family has at least one car. However, a newfound sensibility to environmental problems and the economic situation lead to the reduction of consumption, pollution and costs, with the consequence of discouraging the use of the car. Current research trends aim at making the rail network, the underground and the autopilot tramway network integrated through quick and easy connections among stations. A new concept is also related to the collective use of the private vehicle together with the improvement of the collective use of public transport. It consists of making a certain number of cars available to the public, to be used with special cards and in certain ways. This system is suitable for using electricity. Other types of interventions to mitigate pollution and to encourage the development of new forms of communication are represented by cycle paths recovering disused routes that would lead users to rediscover the charm of walks in the open air. The problem of solving single 
and mass mobility problems represents one of the actual parts of the new urban planning, involving both individual districts and large cities.

\subsection{Mobility, transport and territory}

According to Turner [16], the term "greenway" refers to a "pleasant path from the environmental point of view". This definition derives from the analysis of the term "greenway", which is made up of two words:

- green, indicating vegetated elements appreciable from an environmental, naturalistic, historical-architectural and cultural point of view;

- way, relating to the communication routes (roads, railways, rivers, etc.) and referring to an idea of movement, communication, activity.

During recent decades, a cultural movement has been developed and it is known as the "greenways movement". Moreover, different approaches to the concept of greenway have been widespread. According to article 1 of the statute of the Italian Greenways Association [17], "the term Greenways can be interpreted as a system of linear territories connected to each other that are protected, managed and developed in order to obtain benefits in terms of a recreational, ecological and historical point of view". Concerning the concept of mobility, in the same document in article 2 it is said that "the greenways can constitute a system of paths dedicated to a non-motorized circulation able to connect populations with the resources of the territory (natural, agricultural, landscape, historical-cultural) and with the "centers of life" of urban settlements, both in cities and in rural areas" [17].

The "Lille Declaration" agreement of 2000 [18], signed by the main European associations that operate on the sustainable transport topic, states that the greenways "must have wide, sloping and paved features as to guarantee mixed use in safe conditions by all types of users in any physical condition. In this sense, the reuse of the towpaths of the canals and abandoned railway lines represents the preferred space for the development of greenways". For this reason, the reuse of abandoned railway lines has also been strongly encouraged by one of the main important Italian railway companies, "Ferrovie dello stato" (FS), which in 2003 commissioned a study recollecting the amount of disused railway sections in order to promote their recovery and conversion into slow-moving routes. In this context, the greenway concept refers not only to a simple cycle path but also to the enhancement and requalification of natural resources, the promotion of sustainable development, the recovery of degraded landscapes and the harmonious development of cities. Moreover, the greenway would be used not only by cyclists but also by all non-motorized users.

The most important characteristics of greenways are:

- security, as paths physically separate the dedicated road network;

- accessibility for all types of users (pedestrians, cyclists, hikers on horseback, etc.);

- "sweet circulation", linked for example to moderate slopes, which offer the opportunity to appreciate surrounding landscapes;

- recovery of existing infrastructures and structures, such as paths, historic roads, towpaths, disused railway lines, minor rural roads, etc., for the realization of paths and service structures (rest and refreshment points, information points and others);

- integration with the natural environment.

Greenways, in general, can bring ample benefits to the population involved, such as: 
- contributing to the development of rural regions, bringing wealth and incentives for the creation of new business activities;

- promoting outdoor activities;

- developing an active, responsible and sustainable form of tourism;

- promoting respect for the environment;

- improving mobility in urban and peri-urban areas, creating a system of routes reserved for non-motorized users, and thus helping to improve the quality of life in cities;

- promoting the knowledge and enhancement of the historical, artistic, architectural, cultural, environmental and landscape heritage.

\subsection{The case study}

The part of southern Italy called "Riviera dei Cedri" (Cedar coast) (Fig. 1(a)), which is located along the north-western coast of Calabria for over $70 \mathrm{~km}$ between the town of Tortora and the municipality of Paola, is chosen for this case study. The area is characterized by a heterogeneous landscape with promontories, cliffs, bays in the northern part and wide and flat beaches in the southern part. From an economical point of view, this part of the coast has been affected by large tourist flows over the years and by consequent wild urbanization mainly linked to the Italian phenomenon defined as the "building boom", especially concentrated during the 1970s and 1980s.

The design proposal illustrated in this paper involves a $15 \mathrm{~km}$-long part of the coast among the towns of San Nicola Arcella, Scalea and Santa Maria del Cedro (Fig. 1(b)), with the aim of deepening the feasibility of a "slow" connection between the three inhabited centers through a cycle-pedestrian path. The three chosen towns host a total population of about 18,000 residents, which increases tenfold during the summer, due to the massive presence of tourists.

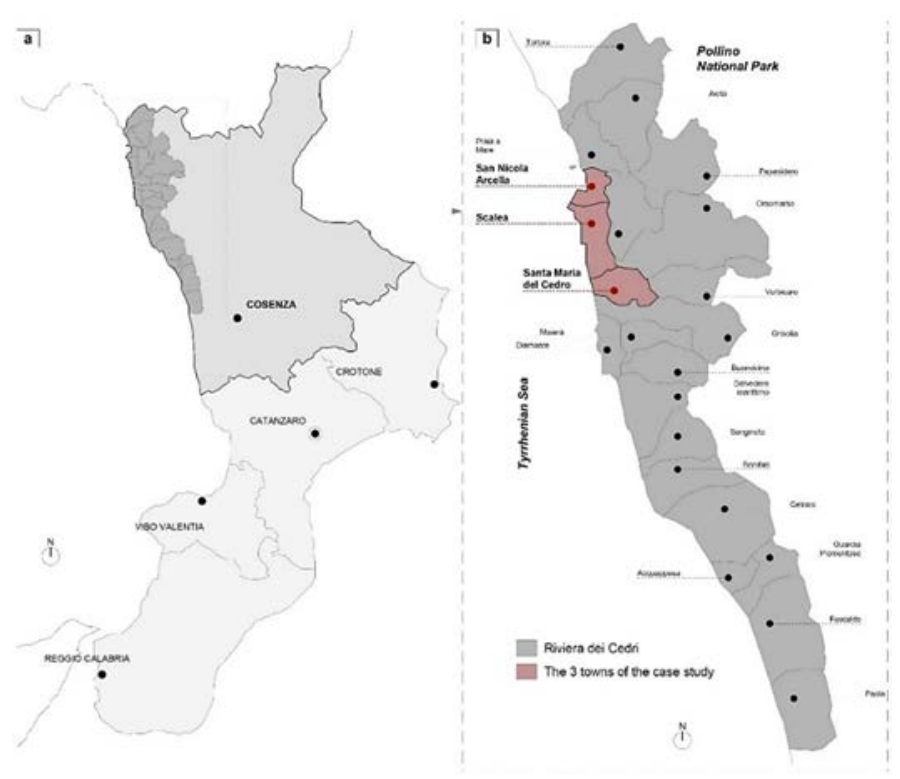

Figure 1: (a) Location of Calabria; (b) Location of "Riviera dei Cedri" (Cedar coast) and the three towns chosen as part of this case study. 
San Nicola Arcella (Fig. 2(a) and (b)) offers coastal landscapes with cliffs, caves, marine bays and scenic trails inserted in protected areas, and its economy is essentially based on summer tourism. Scalea (Fig. 2(c) and (d)) is characterized by a prestigious historical center, almost abandoned and in decay, and by a large flat area in the southern part of town with residential areas, bathing facilities and beaches. Santa Maria del Cedro (Fig. 2(e) and (f)), located in the south of the chosen area, appears as the continuation of Scalea municipality towards the south and it is defined by the presence of three small urban centers that are politically linked to the same center but remain functionally independent.
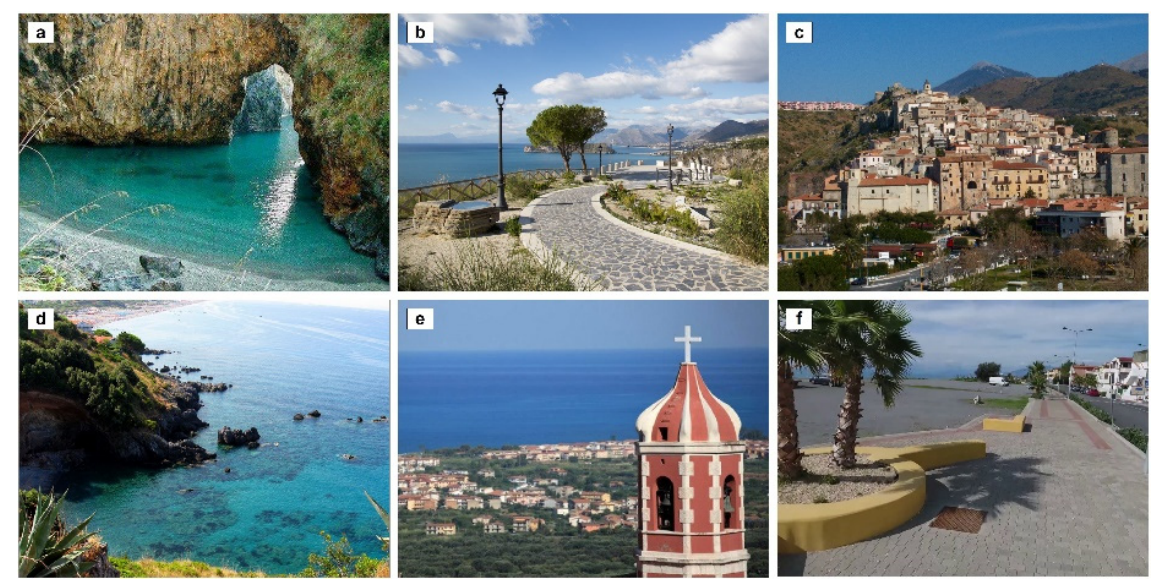

Figure 2: Panoramic views of the towns of: (a) and (b) San Nicola Arcella; (c) and (d) Scalea; (e) and (f) Santa Maria del Cedro.

Thus, beaches, caves, cliffs and Mediterranean vegetation, together with the historical city centers and the proximity to the Pollino National Park, present the principal touristic attractions. In order to enjoy the mentioned natural resources and to begin new tourist scenarios aimed at the sustainable fruition of the landscape and natural environment through trekking, hiking and tourism cycle activities, a recovery of the abandoned railway infrastructures is necessary to create new green paths connecting the three towns mentioned.

\subsection{Railway settlement}

In the case study area, mobility is composed of interconnections and the internal and external mobility of the road network, by the railway line and a little cycle path. The main road is the north-south route called "S.S.18" (state highway) which runs parallel to the coast and serves the city centers along the coast (Fig. 3(a)).

The main railway network is the "Southern Tyrrhenian", one that represents the principal axis connecting the island of Sicily to the rest of the Italian territory. Moreover, it represents the southern section of "Corridor 1Berlin-Palermo" of the trans-European conventional rail network TEN-T. Its southern part, between the towns of Rosarno and San Lucido, is also used as an RFI ("Rete Ferroviaria Italiana", which means Italian railway network) freight route between Gioia Tauro Port and Adriatic-Tyrrhenian ridge, which carries out almost of the north-south connections (with double electrified track). This railway line connects the high Tyrrhenian coast with important cities of southern Italy such as Reggio Calabria, Salerno 
and Naples, offering an important support to the flow of seasonal tourists and to a limited number of commuters who travel daily to reach their job centers. In terms of air traffic, the airfield in the area, situated in front of the Lao River, remains unused.

In general, transport in the chosen area is determined by a lack of slow mobility infrastructures with a scarce endowment of slow mobility tracks, which is in opposition to the situation of about 60 years ago when the pedestrian paths were the main internal mobility branches of the area. With the advent of progress and the spread of the motor vehicle, which also happened in the rest of Italy, a connection network was developed based on motorized transport, which supplanted the pedestrian and bicycle path.

In the project area under examination, the only existing cycle path, of $2 \mathrm{~km}$, is located in the town of Scalea, running parallel to the coast and to the S.S.18, connecting the urban area to subways in order to avoid crossing the state highway. Nevertheless, the cycle path is disconnected from the historical center and to the urban pedestrian paths presenting in the modern city (Fig. 3(a)). The creation of a surface pedestrian and cycle route is not currently present due to the difficult geomorphological conditions of the territory, with high gradients and the promontory among the three selected towns. The geomorphological situation is composed of the presence of mountainous areas close to the coast in the northern part. The coastline is characterized by a promontory with high cliffs overlooking the sea, as well as cliffs, bays and inlets followed by a flat area of alluvial origin generated by the Lao river in the area of Scalea and Santa Maria del Cedro and by the coast, which in that section assumes a flat character with long and wide beaches. Thus, the design proposal, in order to avoid the orographic difficulties described (Fig. 3(b)), finds the solution in the reuse of the old railway line that was used up until the 1960s, crossing the promontory between San Nicola Arcella and Scalea with a series of tunnels and bridges, maintaining a height between 20 and $37 \mathrm{~m}$ above sea level.

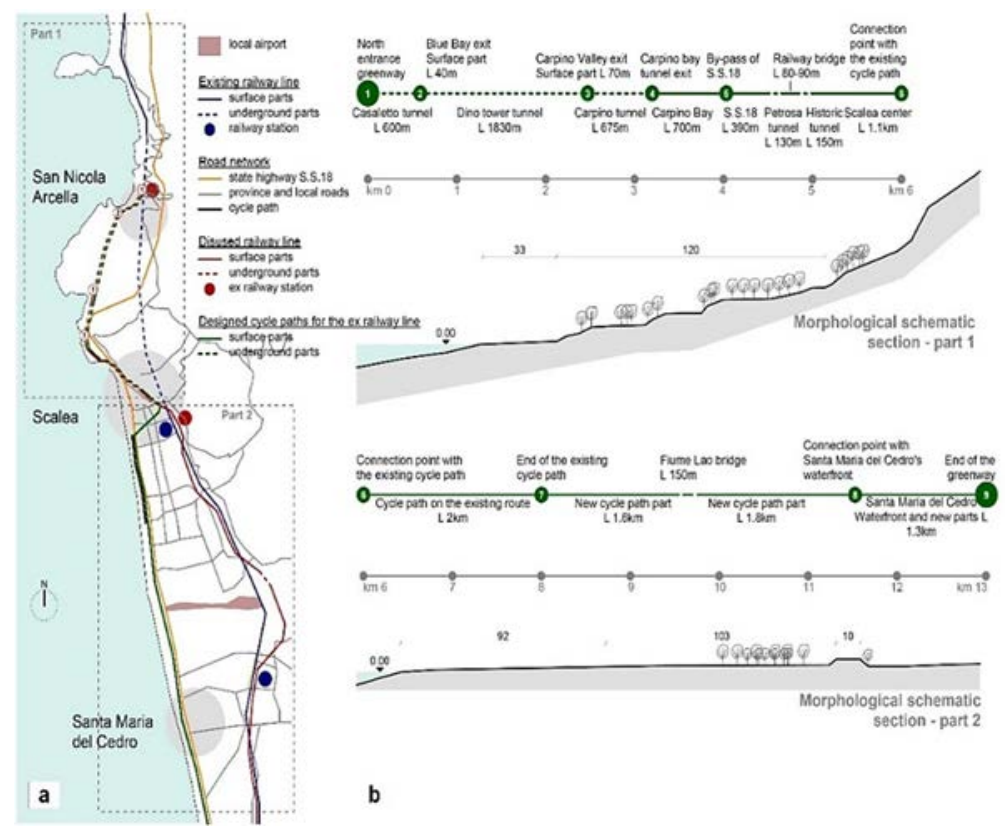

Figure 3: (a) Existing and design connections; (b) Morphological sections of the proposed design cycle path in two different parts. 
Thanks to the disused railway, the historical center of Scalea was crossed through tunnels close to the historical Cimalonga Tower (Fig. 4(a)). In the 1960s, as a result of the transition from the single track to the double track, the old route that passed under the historic center was abandoned in favor of a new route located in the eastern part of Scalea, connecting Scalea to Praia a Mare. In relation to that event, Scalea railway station was moved about 100 meters further south, where it is still located today.
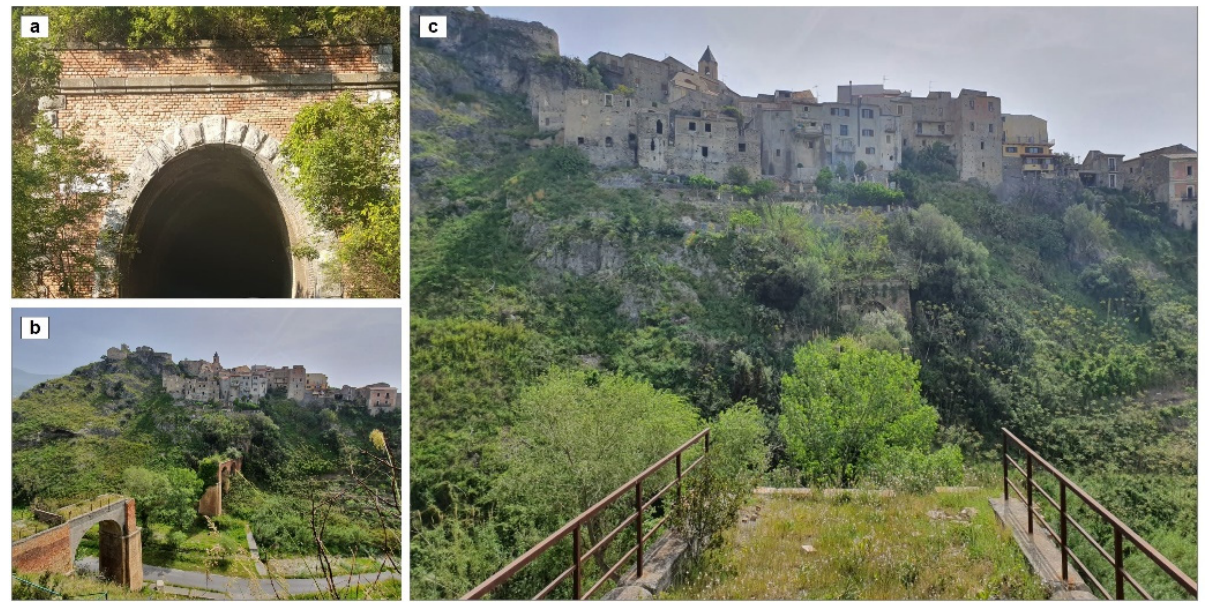

Figure 4: (a) Tunnel close the Cimalonga Tower in Scalea historical center; (b) and (c) Existing railway bridge in Scalea.

\section{DESIGN PROPOSAL}

The design proposal is based on the reuse of the existing and abandoned railway line. In particular, disused tunnels and bridges would be integrated in the design green path. Tunnels are located in areas corresponding to promontories and close to the beaches, having a great naturalistic and touristic interest. The greenway, in this way, will cross the promontory and easily continue on the flat part constituting a pedestrian cycle route of about $13 \mathrm{~km}$.

The entire infrastructure would be enriched with street furniture consisting of benches, baskets, drinking water fountains and bicycle racks; rest areas will be equipped with furniture of eco-compatible materials such as wood and local natural stone; lighting will be defined by LED tunnel lights and photovoltaic charging lamps on the surface sections. Touristic information totems with photographs and historical descriptions will be located throughout the entire greenway. They could also implement a QR-code in order to facilitate the reading of the most important information. Closer areas to the greenway will be integrated with Mediterranean vegetation, trees and shrub essences, creating a "linear park", also equipped with furnishings suitable for outdoor sports activities.

\subsection{Design technical aspects}

The design proposal will include:

- gallery reuse: structural reinforcement where necessary; cleaning and reconstruction of superficial lesions in the vaults; lighting, security and ventilation system; laying gates at tunnel entrances for night-time closure, safety and tourist signs; 
- surface areas: reconstruction of the road surface with eco-compatible materials; construction of ducts for rainwater; safety signs and tourist signs for points of interest; inclusion of urban furniture;

- mixed routes: maintenance and/or reconstruction of the road surface; vertical and horizontal safety signs; satin-colored cycle-pedestrian crossings; introduction of speed bumps for vehicles; improvement of lighting, racks in interchange nodes and parking areas;

- new constructions: in Scalea and Santa Maria del Cedro, to follow the existing cycle path of approximately $2 \mathrm{~km}$, construction of stable bottom platform; water channels; top layer construction in eco-friendly and draining materials; lighting and street furniture; planting of greenery and trees; laying of safety and tourist signs. The cycle path consists of a path running from scratch for about $1.5 \mathrm{~km}$ in a flat area free of obstacles up to the Lao river, parallel to the S.S.18, at a lower level than the state road, decreasing the risk of interference with vehicles and obtaining immediate access to the beaches. It will also contain separate paths among pedestrian and bicycles.

Bridges play an important role: one bridge is already existing, and two ones will be rebuilt in order to ensure the continuity of the connection along the entire route.

- existing railway bridge in Scalea: it is a bridge of about $80 \mathrm{~m}$ in length, consisting of two masonry shoulders with arches and a central part consisting of an iron truss beam of about $40 \mathrm{~m}$ (Fig. 4(b) and (c)). After the decommissioning of the railway section, the iron truss was sold and, today, only the masonry part remains. A reconstruction of the bridge is therefore hypothesized through the insertion of a new reticular structure leaning against the existing masonry structures, in addition to the construction of a parapet and lighting insertions. The bridge in question is located in a suggestive position, $20 \mathrm{~m}$ up the ground level between two promontories, with the sea to the west and the center on the opposite side. The recovery of the bridge would have a notable impact also on the urban layout of Scalea - in fact, it would guarantee the connection between the two ridges where the existing urban areas are actually isolated. After the bridge, the route crosses the hill underground with a tunnel of about $150 \mathrm{~m}$. Then, the greenway enters the urban area and could continue through a mixed cycle/driveway path through the consolidated urban fabric of the modern part of Scalea, connecting places of interest such as the pedestrian area in the city center, the promenade, the railway station, the commercial area, the existing cycle path and the touristic Talao tower.

- bridges on Lao and Abatemarco rivers: in order to overcome the Lao river, the construction of a bridge is suggested. The greenway could run parallel to the S.S.18 through a bridge built with a steel structure and a walkable wooden floor or with eco-compatible materials to minimize the environmental impact. Once this obstacle is overcome, the greenway will develop for another $1.8 \mathrm{~km}$ approximately parallel to the S.S.18 until reach Santa Maria del Cedro town and crossing the following Abatermarco River through the construction of a small bridge in wood or steel.

\subsection{Expected results}

This study conducted aims to highlight the importance of accessibility and usability of the coastal landscape and ancient villages for the large-scale urban redevelopment of southern territories. The improvement of access to the beaches and cliffs of the coast, even of those areas that today are more difficult to reach, are encouraged through the development of cyclo-tourism and hiking along the coast thanks to the greenway, correlating those activities 
with trekking and jogging paths already existing in the nearby Pollino National Park. Through the greenway, the connection between urban areas, historical centers and coastal paths would be guaranteed (Fig. 5). In the case of the historic center of Scalea, through the greenway, it would be reconnected with the urban fabric of the modern city with significant benefits in terms of overall urban regeneration. On a large scale, the inter-municipal mobility system would be strengthened with a consequent contraction of the local territorial map in terms of temporal distances making the different locations closer than they physically are.
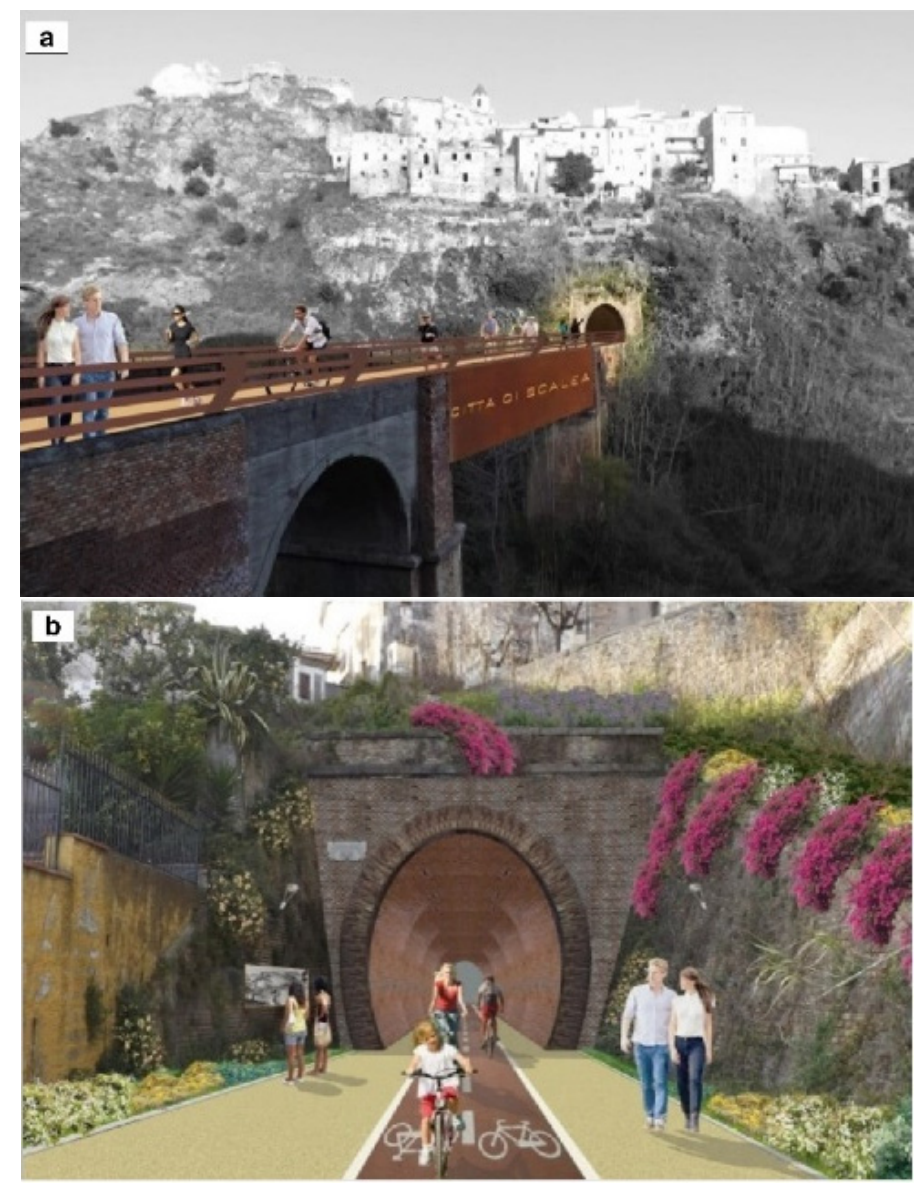

Figure 5: Expected results of the greenway. (a) Reconstruction of the railway bridge in Scalea; (b) Reutilization of the abandoned tunnels through mixed activities.

Even at the economic level, the new infrastructure dedicated to slow mobility would have a good impact on the territory, starting from the expansion of the tourist offers and the specification of new sport activities, but also offering new opportunities for entrepreneurial activities linked to the sustainable use of territory. The vehicular traffic level would be decreased with beneficial effects on the pollution and traffic congestion. The reuse of disused infrastructures would be a sustainable example of the principle of the reduction of land consumption. 


\section{CONCLUSIONS}

Finding a new use for neglected infrastructures, such as disused railways, provides an opportunity for low carbon travel experiences as reconversion policies promote new uses, arrest decay processes and re-establish continuity in the environmental system, using existing linear infrastructures.

The present study offers a design proposal to answer a demand for sustainable transportation systems' planning coming from the south of Italy, where a disused railway line would be replaced by cycle and pedestrian paths.

The main objective of the study is to develop a methodological framework able to support collaborative planning and decision-making processes related to the requalification of disused railways in mixed urban and rural contexts. Another objective is to provide an example to the local governments with reference to the best requalification option for one of the abandoned railway lines in the chosen case study territory. Thus, the study has an innovative value and may increase the use by governments to support the evaluation of environmental impacts of different transportation systems, in order to increase the touristic vocation of southern Italy.

\section{ACKNOWLEDGEMENTS}

Thanks to the "Universidad de La Sabana" (Colombia) for economically supporting the present research and to the "Sapienza University" and "Università degli Studi Link Campus University" (Italy).

[1] United Nations (UN), Sustainable Development Goals. https://sustainabledevelopment.un.org/sdgs.

[2] Matos, P., Vieira, J., Rocha, B., Branquinho, C. \& Pinho, P., Modeling the provision of air-quality regulation ecosystem service provided by urban green spaces using lichens as ecological indicators. Science of the Total Environment, 665, pp. 521-530, 2019.

[3] Environmental Protection Agency (EPA), Greenhouse gas emissions and sinks. www.epa.gov/ghgemissions/inventory-us-greenhouse-gas-emissions-and-sinks.

[4] Catapano, F., Costa, M., Marseglia, G., Sementa, P., Sorge, U. \& Vaglieco, B.M., An experimental and numerical investigation of GDI spray impact over walls at different temperatures. SAE Technical Paper 2016-01-0853, 2016.

DOI:10.4271/2016-01-0853.

[5] Qiu, G., Song, R. \& He, S., The aggravation of urban air quality deterioration due to urbanization, transportation and economic development - Panel models with marginal effect analyses across China. Science of the Total Environment, 651, pp. 1114-1125, 2019.

[6] Laurino, A., Ramella, F. \& Beria, P., The economic regulation of railway networks: A worldwide survey. Transportation Research Part A, 77, pp. 202-212, 2015.

[7] Letot, C., Soleimanmeigouni, I., Ahmadi, A. \& Dehombreux, P., An adaptive opportunistic maintenance model based on railway track condition prediction. IFAC Papers online, 49(28), pp. 120-125, 2016.

[8] Lusby, M.R., Haahr, J.T., Larsen, J., \& Pisinger, D.A., Branch-and-Price algorithm for railway rolling stock rescheduling. Transportation Research Part B, 99, pp. 228-250, 2017.

[9] Noh, Y., Does converting abandoned railways to greenways impact neighboring housing prices?. Landscape and Urban Planning, 183, pp. 157-166, 2019. 
[10] Zhang, L., Zhang, J., Duan, Z.Y. \& Bryde, D., Sustainable bike-sharing systems: characteristics and commonalities across cases in urban China. Journal of Cleaner Production, 97, pp. 124-133, 2015.

[11] Marzano, V., Tocchia, D., Papola, A., Aponte, D., Simonelli, F. \& Cascetta, E., Incentives to freight railway undertakings compensating for infrastructural gaps: Methodology and practical application to Italy. Transportation Research Part A, 110, pp. 177-188, 2018.

[12] De Martinis, V. \& Corman, F., Data-driven perspectives for energy efficient operations in railway systems: Current practices and future opportunities. Transportation Research Part C, 95, pp. 679-697, 2018.

[13] Ferretti, V. \& Degioanni, A., How to support the design and evaluation of redevelopment projects for disused railways? A methodological proposal and key lessons learned. Transportation Research Part D, 52, pp. 29-48, 2017.

[14] Cutini, A., L'urbanistica delle Reti, vol. 1, 2014.

[15] Galiano, G., L'infrastruttura Ferroviaria e le Trasformazioni Territoriali (The railway infrastructure and territorial transformations). Master's thesis, Sapienza University: Rome, 2012.

[16] Turner, T., Greenways, blueways, skyways and other ways to a better London. Landscape and Urban Planning, 33, pp. 269-282, 1995.

[17] National Assembly of AIG members in Milan, Regulation of the Italian Greenways Association, 1999.

[18] Dichiarazione di Lille. Per lo sviluppo di una rete Europea greenway (For the development of a European greenway network), 2000. 